\title{
Spatial distributions of anchovy larvae and naupliar copepods in relation to frontal eddies
}

YUI OKAZAKI, ${ }^{1 *}$ HIDEAKI NAKATA, ${ }^{1}$ AND SHINGO KIMURA ${ }^{2}$

${ }^{\prime}$ Faculty of Fisheries, Nagasaki University, Nagasaki 852-8521, Japan (f1333@cc.nagasaki-u.ac.jp), ${ }^{2}$ Ocean Research Institute, University of Tokyo, Tokyo 164-8639, Japan

KEYWORDS: anchovy larvae, naupliar copepods, frontal eddies, Kuroshio

\section{INTRODUCTION}

Cyclonic frontal eddies are often recognized along the frontal area of the Kuroshio and Kuroshio Extension. These eddies may contribute to both upwelling of nutrient-rich deep water and horizontal entrainment of fish larvae into the eddy region. ${ }^{1,2)}$ The main objective of our study is to look at the effects of frontal eddy on the distribution of anchovy (Engraulis japonicus) larvae and their prey organisms.

\section{MATERIAL AND METHODS}

Observations of a frontal region of the Kuroshio and the Kuroshio Extension were conducted during May 1997 and May 1999 (Fig. 1). In each observation, temperature and salinity observations were measured with a CTD cast. Larvae were collected using the Ocean Research Institute (ORI) net ${ }^{3)}$ with $1.6 \mathrm{~m}$ diameter and $0.33 \mathrm{~mm}$ mesh size. The ORI net was towed at the surface for 3-5 min at a speed of $1 \mathrm{~m} / \mathrm{s}$. Larval samples were fixed in $2.5 \%$ seawater glutaraldehyde. Larval prey (mainly naupliar copepods) was collected from the surface water (1-liter) using a bucket simultaneously with the surface net towing. The larval prey samples were fixed in $5 \%$ seawater formalin after concentrated by a plankton net with $0.020 \mathrm{~mm}$ mesh. In the Kuroshio Extension, observation was conducted along a drifting route of a surface buoy released from the eddy center to trace the time change in the physical

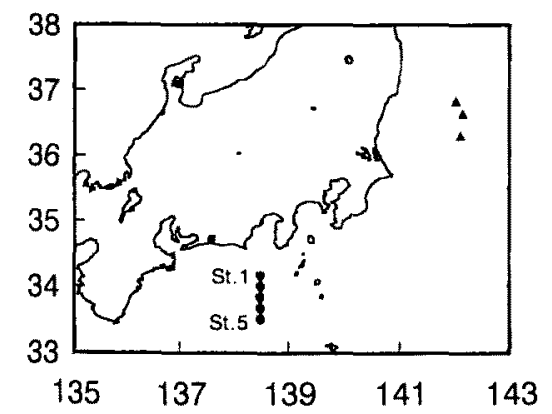

Fig. 1 Map of stations during May 1997 and May 1999. and biological characteristics. Surface water samples $(200 \mathrm{ml})$ for determining chlorophyll- $a$ concentration were filtered through a Whatman $\mathrm{GF} / \mathrm{F}$ filter. Chlorophyll- $a$ on the filter was extracted in dimethylformamide and then measured using the fluorometric method.

\section{RESULTS}

It was inferred from dome shape isotherm distribution along the Enshu-nada Line (St.1-5) that upwelling was induced by a frontal eddy (Fig. 2). Peak of larval anchovy abundance at St. 4 apparently coincided with the periphery of the eddy. However, naupliar copepod densities were low in and around the frontal eddy compared to the most coastal station (St.1, Fig. 2).

On the other hand, Figure 3 demonstrates time changes in the distribution of chlorophyll-a concentration and naupliar copepod densities in the surface water of the eddy in the Kuroshio Extension.

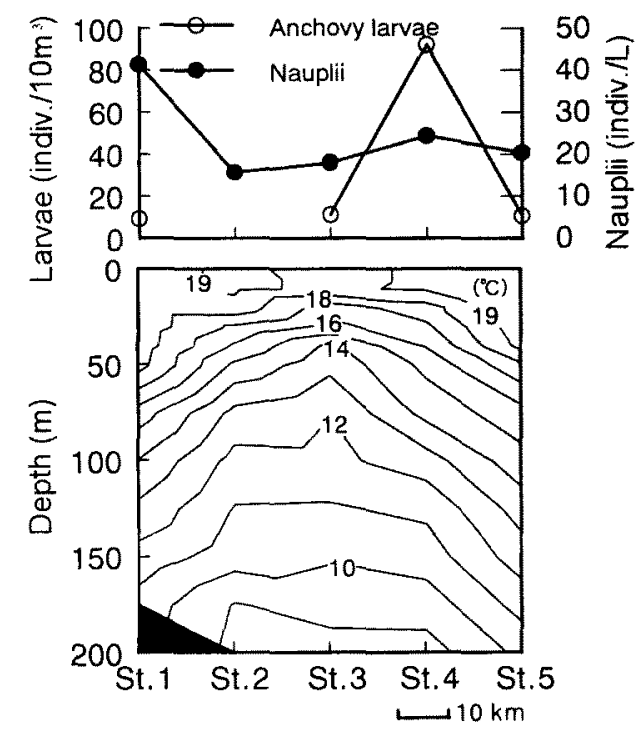

Fig. 2 Surface distributions of anchovy larvae and naupliar copepods (upper panel) and vertical profile of sea temperature (lower panel) in Enshu-nada Sea in May 1997. 
During one day tracking of a drifting buoy, we detected a marked upwelling induced by a frontal eddy. Corresponding to the upwelling, concentrations of chlorophyll- $a$ were high at first day (Day 0 in Fig. 3 ), however they gradually decreased with time. On the contrary, naupliar copepod densities on the same stations evidently increased (Fig. 3).

\section{DISCUSSION}

Entrainment of fish larvae into the cyclonic eddy as seen in the present study was also reported off Hawaii Island, ${ }^{4)}$ off Northern Africa ${ }^{5)}$ and in a Kuroshio frontal eddy. ${ }^{2)}$ It should be noted in our results that anchovy larvae were most abundant in the periphery of the eddy in the Enshu-nada Sea. Although detail of the physical mechanism has not yet clarified, divergence of the surface water due to the upwelling at the eddy center may have implication for this larval aggregation.

It has been reported that due to upwelling of nutrient-rich deep water to the surface euphotic zone, primary production tends to be enhanced in the frontal eddy regions. ${ }^{1,6)}$ Further, marked increase of copepod production in the upwelling region has been reported in the coastal area of Izu Islands ${ }^{7}$ and in the Kuroshio frontal eddy. ${ }^{2)}$ Our results in the Kuroshio Extension also show that naupliar copepod abundance in the frontal eddy became about 2-fold during one day. Egg production of smaller copepods such as Paracalanus sp. would be enhanced within a few days responding to the increase in food concentration. ${ }^{8.9)}$ This suggests that marked increase in the abundance of naupliar copepods in the frontal eddy could occur within a few days responding to the increase in food concentration.

The survival of larval fish in oligotrophic oceanic water such as the Kuroshio and Kuroshio Extension region could therefore greatly depend on whether and how frequent they encounter with the frontal eddy. Namely, the frontal eddy could prevent the larvae from dispersing to unproductive offshore water by its function of entrainment and entrapment, and provide a favorable feeding ground due to high production induced by upwelling. These functions of the frontal eddy possibly benefit the growth and survival of fish larvae in the offshore open ocean.

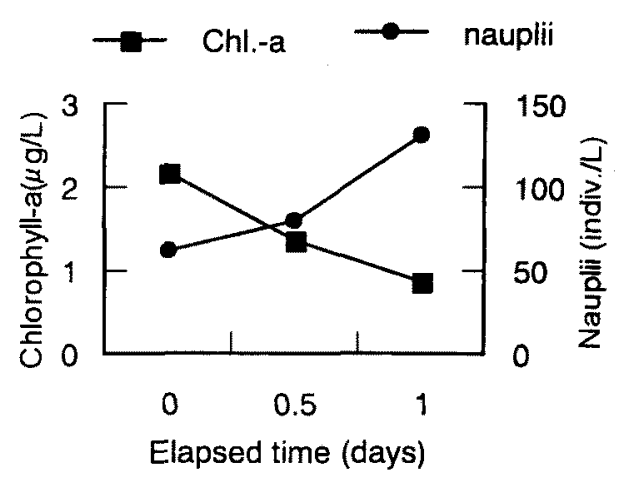

Fig. 3 Time changes in the chlorophyll-a concentration and abundance of naupliar copepods in the surface water of the eddy center in the Kuroshio Extension in May 1999.

\section{REFERENCES}

1. Kimura S, Kasai A, Nakata $H$, Sugimoto $T$, Simpson JH, Cheok JVS. Biological productivity of meso-scale eddies caused by frontal distributions in the Kuroshio. ICES J. Mar. Sci. 1997;54: 179-192.

2. Nakata H, Kimura S, Okazaki Y, Kasai A. Implications of meso-scale eddies caused by frontal disturbance of the Kuroshio Current for anchovy recruitment. ICES J. Mar. Sci. 2000;57: 143-152.

3. Omori M. A $160-\mathrm{cm}$ opening-closing plankton net- I. Description of gear. J Oceanogr Soc Japan. 1965; 21: 20-28.

4. Lobel P S, Robinson A R. Transport and entrapment of fish larvae by ocean mesoscale eddies and currents in Hawaiian waters. Deep Sea Res. 1986; 33: 483-500.

5. Rodríguez J M, Hernándes-León S, Barton E D. Mesoscale distribution of fish larvae in relation to an upwelling filament off Northwest Africa. Deep Sea Research. 1999;46: 1969-1984.

6. Lee $\mathrm{T} \mathrm{N}$, Atkinson L, Legeckis R. Observations of a Gulf Stream frontal eddy on the Georgia continental shelf, April 1977. Deep Sea Res. 1981;28: 347-378.

7. Toda H. Surface distributions of copepods in relation to regional upwellings around the lzu Islands in summer of 1988. Journal of the Oceanographical Society of Japan. 1989;45: 254-257.

8. Checkley $D$ M Jr.. Food limitation of egg production by a marine plankton copepod in the sea off the southern California. Limnology and Oceanography. 1980;25: 991-998.

9. Uye S. Temperature- depend development and growth of the planktonic copepod Paracalanus sp. in the laboratory. Bulletin of Plankton Society of Japan, Special Volume 1991; 627-636. 